\title{
About The Amendment to the Law on Higher Education
}

\section{Dear readers,}

it seems now, that after the years of repeated attempts to amend the law on higher education, the effort gets clearer contours in the form of the extensive amendment to the law. It is true that before this amendment comes into force, it has to pass through the legislative process. Nevertheless, it is possible to ask the question yet, what can the proposed change bring to the university environment.

At the outset, I must say that I am not really sure, whether we actually know, what the weaknesses of our universities are, and the most importantly, whether we do know how to deal with them. In my opinion, the basic problem is that we hear often about the need for fundamental reform of higher education, but the specific reasons are not usually discussed. It seems to me that the conclusion on the state of the whole higher school system is based on the obvious problems and the low level of one school. The analysis restricts to finding that schools are falling behind the world's prestigious universities and instructions slip into "you need to improve quality". These ideas are true, but they are too general for our search for the successful future of our higher education.

If we want to increase the level of our colleges, we have to on the one hand very specifically describe, with knowledge of the conditions of our current higher education, what are the main problems of particular disciplines, and define the objectives we should achieve on the other hand. And then we should deduce the specific steps that will our colleges take to go in the right direction.

If we look at the basic points of the amendment to the law, it cloud seem that it goes in this direction. It cannot be denied that the accent in the changes to law is on improving the quality of higher education, schools themselves should set up a body for internal quality assessment that evaluate the quality and to take measures for quality assurance. Enhancing the status of the National accrediting agency, as a guardian of the level and quality of our higher education, might be considered to be a significant change too. 
However, the important question still remains whether we are actually able to measure quality reliably and meaningfully. The measurement often slips to quantification of what can be quantified (and the meaningfulness of the quantification and implications it will bring stand aside), or it slips to the word rating, which in turn often results into reports which fail to find its attentive readers and does not provide usable information on the current state and ways to improve it in the first place.

This is the main reason why I am quite sceptical whether the creation of an authority for the internal evaluation of quality will bring something new to the situation. The change in the status of the Accreditation Agency will not make itself the difference to its activities. In my opinion, there still remains the question whether the concept of agency of which members come from institutions that are the subject of accreditation, is able objectively to assess the quality of the schools and disciplines. Introduced institutional accreditation might free up capacity for the evaluation of applications for accreditation of schools that require "more attention", but does not solve the above problems.

And so the question remains whether the amendment to the Act will have a real impact on quality of our universities. What is indisputable, however, is a relatively large administrative burden, which will be connected with the new accreditation of programmes, with the establishment of the authority for the internal quality assessment or with changing of many internal regulations of universities.

It's not that the aims embodied in the amendment to the Act were flawed. I am afraid, however, that the changes will take place at the administrative level. The level of schools stems in reality from something else. It is primarily determined by the attitude and the responsibility of students and teachers, their interest and motivation to learn as much as possible, to discover something new and to take care of their school's reputation. And this all cannot be changed by any law. The change can be made only by competition between schools and by the pressure of employers for graduates' standards. It would be therefore better not to expect too much from the change of the law. We would rather not believe too much in the ability of some authority to inspect and review objectively the quality of schools. Let's learn that just as we select a car for its make, we need to choose a college for its name - whether we select a school where we want to study or from where we will employ graduates. We must not forget that as long as there is demand for titles 
PREFACE - Dvořák, P.: About The Amendment to the Law on Higher Education.

without adequate knowledge, there are schools without the required quality. Fortunately, these schools are not determining the level of our higher education!

doc. Ing. Petr DVOŘÁK, Ph.D.

Dean

Faculty of Finance and Accounting, University of Economics, Prague 